\title{
STUDENTS WITH DISABILITIES' EXPERIENCE IN SOUTH AFRICAN HIGHER EDUCATION - A SYNTHESIS OF LITERATURE
}

\author{
O. Mutanga \\ Institute of Health and Society \\ Faculty of Medicine, University of Oslo \\ Oslo, Norway \\ e-mail: oliverm.junior@gmail.com
}

\section{ABSTRACT}

This review article offers a synthesis of published studies on students with disabilities' experience in South African higher education since 1994, when a democratically elected government took office. The article presents a review of published studies describing the experiences of students with disabilities in South African higher education (SAHE) in the period 1994-2017. A synthesis of the findings and implications of South African studies relating to students with disabilities in SAHE is provided. Three aspects will be discussed: (a) conceptualisation of disability; (b) access, inclusion and participation in higher education; and (c) supporting mechanisms for students with disabilities. Challenges, areas needing further study, lessons learnt, approaches and policy implications for policy-practitioners and institutions are suggested.

Keywords: students with disabilities, South Africa, higher education, students' experience, capabilities approach

\section{INTRODUCTION}

The article presents a review of published studies describing the experiences of students with disabilities in South African higher education (SAHE) in the period 1994-2017. A synthesis of the findings and implications of South African studies relating to students with disabilities in SAHE is provided. Three aspects will be discussed: (a) conceptualisation of disability; (b) access, inclusion and participation in higher education; and (c) supporting mechanisms for students with disabilities. I will summarise the key studies and provide an overview of the implications for the reviewed literature, and motivate a capabilities-based inclusive framework to understanding disability. The compilation of these studies has been ongoing since 2013 and it was a result of broad database searches and tracking of references encountered in the reading process. I scanned the literature available on Google Scholar and ProQuest, as well as dissertations on the University of the Free State's library catalogue, using a combination of the search terms 'disability', ‘students with disabilities', ‘access', ‘transformation' and ‘inclusion'. It must be acknowledged that because of the expansive nature of issues in the lives of students 
with disabilities, literature covered here might not be exhaustive. However, the themes generated cover almost all aspects related to the needs of students with disabilities in SAHE. This exercise was motivated by a conviction that attempts to contribute to full inclusion and success of students with disabilities in SAHE will benefit from a holistic understanding of the experiences of students with disabilities, as found in the studies that have been done so far.

Studies on the experiences of students with disabilities in SAHE stem from three main sources: commissioned reports, scholarly articles, and masters and doctoral studies theses. The bulk of these studies are qualitative in nature, focusing mostly on a single case study higher education institution and targeted at a particular type of impairment.

\section{OVERVIEW OF SOUTH AFRICAN LITERATURE}

South Africa has many anti-discriminatory legislative provisions. However, Crous (2004) reports that few people with disabilities participate in higher education and the small number that do access higher education face many challenges. This is partly because policy provisions regarding disability matters are fragmented and currently there is no national policy. In most instances when disability is mentioned in policy documents, either it makes no reference to higher education; or when it does, it is hazy. For example, the National Plan for Higher Education includes students with disabilities as part of 'non-traditional students' along with female and black students (Department of Education 2001). Combining disability with gender and race issues seems to have relegated disability issues to the periphery as racial and (recently) gender matters are given priority as a result of apartheid (Howell 2006). There is thus scant literature on the experiences of students with disabilities in SAHE compared with other countries such as Australia, the UK and the USA. Limited studies in this field might be indicative of the fact that it is still in an exploratory phase in South Africa. Most studies on 'non-traditional students' focus mainly on race (black students) and gender (female students).

\section{CONCEPTUALISING DISABILITY}

The South Africa government asserts that it views disability from the social model perspective. As has been argued by Mutanga and Walker (2015), proponents of the social model seem to have neglected the need to understand the challenges for people with disabilities, not only emanating from the social environment but from other factors such as the individual, environmental, economic and political spheres. As a result of the dominant perspectives on understanding disability, international scholars' attention has now shifted towards developing better understanding of disability by incorporating multiple and intersecting factors (economic, 
social, environmental, political and cultural barriers) that place restrictions in the way of full inclusion and success of students with disabilities in higher education (Strnadova, Hájková and Květoňová 2015). Nonetheless, these studies do not extend to addressing the freedoms and opportunities that individual students with disabilities value in higher education. This is where the capabilities approach as a frame of analysis is important, as it introduces a language of wellbeing and agency, while at the same time taking account of the relationship between each individual's opportunities and the social arrangements which shape that student's ability to convert their capabilities into actual achievements.

The capabilities approach pioneered by Amartya Sen (1999) and developed by Martha Nussbaum (2011) is one of the frameworks that captures complex issues. The approach requires us to look at inclusion as a matter of social justice and to move beyond measuring inclusion through statistics to interrogate each student's freedom and capacity to achieve what he or she values. Within the capabilities perspective, disability occurs when an individual with impairment is deprived of opportunities and freedoms to do what he or she values (Mitra 2006). Nussbaum (2006) argues that justice for people with disabilities should include whatever special arrangements are required for them to lead a dignified life, and the work of caring for them should be socially recognized, fairly distributed, and fairly compensated. The approach moves beyond the dual framing of disability in medical terms (stigmatize) or the social environment (treat all as equal) to a relational approach that considers both individual impairment and educational arrangements, taking into account the specific situation and each student's agency. In this manner it avoids labelling people with disabilities based on their impairment only.

Most South African studies seem to be influenced by the social model. For example, Watermeyer et al. (2006) dedicated a whole edited book to the social oppression of disabled people in South Africa, anchoring their arguments in the social model. Ultimately, this has led to the absence from most studies on the experiences of students with disabilities of the role of impairments in students' capacity to do what they value. Again, as in other international studies, most South African studies have not included the views of students with disabilities in justifying the concepts they choose. For example, Morrison, Brand and Cilliers (2009, 202) say,

for the purposes of this article, the term 'students with disabilities' is preferred to 'students with special educational or learning needs’ for its brevity.

On the other hand, Crous (2004) states that he adopted the term 'students with impairments' because the official South African definition of disability is based on the socio-political 
perspective. Furthermore, Matshedisho (2010) uses the term ‘disabled students’ without giving reasons. Disability is a contested identity (Mutanga 2013). For example, in a study by Bell, Carl and Swart (2016), all participating students identified themselves as having a hearing impairment and viewed themselves as 'normal'. Though it is often reported that the term 'persons with disabilities' is preferred in disability discourse because this puts the person before the condition (Ladau 2015), South African studies have not interrogated how people with disabilities feel about the terminologies in their native languages. For example, if we translate the terms 'disabled students', 'students with disabilities' and 'students with impairments' into Zulu or Sotho, does it make linguistic differences? I now move to the discussion of various studies reviewed in South Africa.

\section{STUDENTS' WITH DISABILITIES' ACCESS AND PARTICIPATION IN HIGHER EDUCATION}

This section traces the historical developments around the inclusion of students with disabilities in SAHE as reported by various scholars. It outlines what the literature says about disabilityrelated policy frameworks for higher education during and after apartheid. This will show how the context of SAHE is important in understanding current equity and inclusion imperatives. IT will also look at studies that focus on physical access challenges in SAHE. I summarise and discuss the studies with reference to the challenges around inclusion.

\section{Apartheid period}

During apartheid, students with disabilities were excluded from the education system. More than 80 per cent of students with disabilities were not in school (DoE 2001). For those that had access to education, the system segregated them into 'special schools' and prevented them from coming into contact with non-disabled students. This was based on the medical approach to disability, which argues that students with disabilities can only flourish in education when specialised care is provided to them by medical professionals (Nel, Engelbrecht, Nel and Tlale 2013). However, a lot of 'special schools' for black students with disabilities were not wellresourced compared to those for white students with disabilities (Naicker 2005). At times, students with disabilities were enrolled in mainstream schools, but had their own 'special classrooms' separate from non-disabled students (Howell and Lazarus 2003; Swart and Pettipher 2011). This exclusionary schooling system did not prepare students with disabilities to enter higher education, and for most, there was no progression after school. The historical imbalances of apartheid and the conceptualisation of disability as an individual problem put 
barriers in the way of full inclusion of students with disabilities in SAHE. The 'special' schools and classrooms were legitimised by the education system and national policies. As such, it is paramount to explore how higher education institutional policies and practices are performing with regards to the inclusion of students with disabilities. For example, we need to ask ourselves the difference between the operations of Disability Units within most higher education institutions and those that established 'special' schools and classrooms.

\section{Post-1994}

Howell (2006) explored the historical context of SAHE. She notes that because of apartheid, post-1994 equity policies have largely focused on increasing the participation of black students in higher education. Although access of women and black students to higher education has increased, limited attention has been paid to students with disabilities. As a result, she argues, students with disabilities continue to be excluded from higher education. She goes further, saying that although the schooling system in the post-1994 period has the potential to support greater participation of students with disabilities in higher education, barriers remain. Moving beyond analysis of policy developments, some studies explore the experiences of students with disabilities. Howell and Lazarus (2003) explored the challenges faced by SAHE in increasing access and participation for students with disabilities in the wake of White Paper 6 and the National Plan for Higher Education. They maintain that some of the reasons for continued inclusion challenges for students with disabilities are that inequalities for students with disabilities in higher education are linked to their schooling experiences. In addition, barriers within higher education relate to attitudes to disability, academic curricula, physical environments, teaching and learning support, and the allocation and distribution of resources.

Howell and Lazarus (2003) further argue that in addressing the challenges of increasing access and participation of students with disabilities in SAHE, more needs to be done to attend to issues of student diversity and other challenges confronting higher education. They are clear that increasing student participation should be differentiated from making students fit into an unchanging education system. They state that policies should aim to accommodate a larger and more diverse population. Matshedisho (2007a) also looked at the challenges of support for students with disabilities in SAHE. Most of the challenges he raises are similar to those noted by Howell (2005), and include lack of funding, lack of data on students with disabilities and the slow pace of transformation in higher education. A lack of change within higher education was also highlighted by Bell (2013) in a study on the teaching and learning support for students with hearing impairment at a university in the Western Cape. 
In his study, Matshedisho (2007b) interrogates the challenges of access to higher education for students with disabilities from a human rights perspective. He states that one of the difficulties of redressing unequal access to higher education for students with disabilities arises out of the challenge of transforming formal rights on paper into real rights. He says that the SAHE system has been systematic in perpetuating structural inequalities and social injustice. To resolve this, three points are raised: the need to transform policies so that they address ideological impediments to what constitutes reasonable support; formal rights do not automatically make rights real to people; and the need to involve academic staff in decisionmaking processes about support for students with disabilities. Matshedisho notes that South Africa seems to be moving along a contradictory path of espousing disability rights and the social model of disability, yet remaining embedded in the practice and legacy of 'benevolence'. He posits that this is evident from the challenges that disability support services face and the lack of political commitment to disability issues by government and higher education. Part of dealing with the problem is to have a disability policy for higher education institutions and to prioritise disability as part of redressing social inequalities in South Africa. While he seems to blame acts of benevolence, these acts are not inherently negative; however, they should not be the sole solutions to better provision for students with disabilities in higher education.

Again, since the promulgation of the 2014 White Paper, it seems the government (through the Department of Higher Education and Training) is now more committed to improve access, inclusion and success of students with disabilities in higher education. A framework requiring all higher education institutions to develop clear plans to address disability matters within their contexts is already being formulated by a Ministerial Task team.

Commissioned by the Council on Higher Education, Howell (2005) reported on issues of access, policy framework and participation of students with disabilities in higher education. The study was based on questionnaires posted to administrative staff at various higher education institutions. Although the study targeted all higher education institutions, only a few institutions responded. The report highlights four challenges faced by higher education institutions in addressing access issues for students with disabilities: failure to design and implement a disability policy; a legacy of exclusion of students with disabilities at all levels of education (apartheid); attitudinal barriers; and a lack of reliable data on students with disabilities in SAHE. This report highlights differences in the commitment of staff to attend to disability matters, in both historically black and historically white institutions. This report also highlights key concerns regarding SAHE e.g. the need to overcome a history of unequal provision due to the legacy of apartheid, and the lack of integration of support services for students with disabilities 
into the core functioning of higher education institutions. This literature must be understood in the context of that historical background. These studies are connected, in that they mostly present the policy and historical trajectories of SAHE and the reasons for continuing challenges, even in the wake of new policy frameworks. Different solutions are suggested, including a national disability policy framework for higher education, as in the UK and Australia. These studies emphasise strongly the complex nature of the environment within which disability occurs. As such, national policies ought to make different provisions for historicallyadvantaged white institutions and historically-disadvantaged black institutions. One of the areas that has received a lot of attention from researchers in South Africa is physical access challenges faced by students with disabilities in SAHE.

\section{Physical access challenges}

One of the greatest challenges faced by students with disabilities within higher education is physical access. Tugli, Zungu, Goon and Anyanwu (2013) assessed the perceptions of students with disabilities concerning access and support at the University of Venda. Participating students highlighted challenges pertaining to facilities, student support material and physical access within the university environment. Twenty-eight students affirmed that the physical environment constituted a great barrier to their learning, and more than half maintained that the physical environment made them vulnerable or unsafe. Tugli et al. (2013) conclude that increased access and support services are needed at university to allow equal participation in social and academic life. In another study, Ntombela and Soobrayen, (2013) explored the nature of access challenges faced by visually-impaired students at the Edgewood campus of the University of KwaZulu-Natal. Two Disability Unit staff were interviewed and institutional documents were analysed. Findings show that although access has improved for students with disabilities at this university, there are still systemic barriers that limit the participation of students with visual impairments in the academic programs. Some of these challenges emanate from understaffing at the Disability Unit, which negatively affect support provision. Other challenges relate to the curriculum e.g. placements of visually-impaired students who are enrolled for Education course at schools where there are no auxiliary teacher aides. They conclude that improved access requires partnership between government and higher education institutions to monitor and support systemic transformation.

On a positive note, Fitchett (2015) reports that a particular South African higher education institution has started to build new structures with access for people with disabilities in mind. Despite this development, students with disabilities who were interviewed reported that the new 
buildings are still problematic because there is too much space between the sitting areas, the podium and the board. Similarly, Phukubje and Ngoepe's study (2016) concluded that even though a purpose-built library service unit for students with disabilities that complies with international best practice was established, students with disabilities were not satisfied with the library services they received, as very little material had been transcribed into accessible formats. Furthermore, only one librarian was assigned to manage and run the library services for all students with disabilities.

Another study was done by Engelbrecht and De Beer (2014), comprising 23 visually- and mobility-challenged students. The aim of this study was to determine if a group of students living with a physical disability experienced constrained access to a South African higher education institution. Just like Buthelezi's (2014) study on the challenges faced by students with disabilities at a Technical and Vocational Education and Training (FVET) college in KwaZulu Natal, they found that students living with a physical disability experienced accessibility constraints. These challenges were around physical access in the form of accessing the library and parking spaces.

An earlier study by Losinsky, Levi, Saffey and Jelsma (2003) undertook a descriptive cross-sectional study to establish the ease of accessibility to students who use wheelchairs at a university in South Africa. Accessibility was defined both in terms of access to buildings and the added time and distance travelled by wheelchair users on the campus. Five faculties were randomly selected and typical routes travelled by a first year student in each faculty established. Losinsky et al. found that two buildings were fully accessible, while three were completely inaccessible. Inaccessible toilets were the most common problem. Wheelchair users consistently had to travel further and for longer between lecture theatres in all the faculties studied. These students were therefore unable to reach their lectures within the ten minutes allocated by the university. They concluded that the inaccessibility of the buildings limits the full integration of students who use wheelchairs into campus life.

Lastly, in a study reviewing literature on international and South African studies focused on opportunities and obstacles that students with disabilities in professional degrees face, Ndlovu and Walton (2016) concluded that a number of obstacles are still experienced, specifically by students with disabilities, which result in a lack of professional skills amongst persons with disabilities in the South African context.

The studies I have summarised above have some common themes. They all report that physical access is a significant challenge. This is not surprising as the participants in these studies either have visual or mobility challenges. However, what is remarkable is that nearly 
twenty years after Losinsky et al.'s (2003) study, the challenges of physical access still persist in South African higher education. It is not unexpected that students with disabilities make up less than 1 per cent of the total student population in SAHE (FOTIM 2011). Those that make it into higher education have to struggle with physical access (Losinsky et al. 2003; Engelbretch and De Beer 2014; Mutanga and Walker 2015) and attitudinal problems of their peers and staff (Howell 2005). There is no full participation for students with disabilities in SAHE (Lourens 2015; Lourens, McKinney and Swartz 2016). This is despite the fact that it has been a decade since South Africa signed and ratified the Convention on the Rights of Persons with Disabilities (CRPD). The convention is an international human rights treaty that is supposed to protect the rights and dignity of people with disabilities. Among the reasons for low participation in higher education by students with disabilities is limited institutional support, as disability matters are not prioritised by most higher education institutions (Tugli et al. 2013; Ohajunwa, McKenzie, Hardy and Lorenzo 2014) and lack of political commitment from the government (Matshedisho 2007b). As a result of these challenges, it is evident that access to higher education does not guarantee that students with disabilities can access education and success once they arrive at university. Below, I look at what studies say about the support available for students with disabilities in SAHE.

\section{SUPPORTING MECHANISMS FOR STUDENTS WITH DISABILITIES}

South African literature has also focused on different supporting mechanisms available to students with disabilities in higher education. These include support offered through Disability Units and lecturers.

\section{The role of Disability Units}

Disability Units provide some of the services required by students with disabilities in higher education. These include provision of study materials in accessible formats (e.g. Braille or large print); extra time during assessments; and availability of sign language interpreters (FOTIM 2011; Matshedisho 2010; Naidoo 2010). Students with disabilities value the services they receive at the Disability Units. For example, Matshedisho (2010) reported that 25 per cent of students with disabilities in his study felt comfortable and welcomed during their transition into the university as a result of the support given by the Disability Units. In instances where Disability Units did not play a part in providing services, students felt unwelcome at their universities. One of the major studies carried out in South Africa on the service provision for students with disabilities was done by FOTIM (2012) with the aim of describing and analysing 
the role and functions of Disability Units at the different higher education institutions. FOTIM conducted this study across fifteen universities, and key findings include the following:

- $\quad$ There are factors beyond the control of higher education, e.g. the impact of schooling and family backgrounds on the inclusion of students with disabilities in higher education;

- $\quad$ The functions and operations of Disability Units vary across higher education institutions;

- Disability is defined differently within higher education institutions and students are classified differently. The definitions in use suggest a predominance of the medical model of disability;

- At many higher education institutions, disability issues are still managed in fragmented ways, with Disability Units being reactive in their approaches most of the time. Disability issues are largely managed as separate from other diversity and transformation imperatives;

- The proportion of students with disabilities is roughly estimated to be less than 1 per cent of the total student population at the participating institutions. The total number of students with disabilities at the different institutions varies from 21-400 or less than 2 per cent of the total student population, as reported by participants;

- $\quad$ Not all Disability Units cater for all types of impairments. The more established and larger Disability Units lean towards providing services for most impairment needs, while the newer and smaller Disability Units tend to provide services primarily for students with visual or mobility challenges; and

- It was not necessarily the case that the more established longstanding Disability Units had the best practice in place. Howell (2005) found that having more financial capacity does not always equate to best practices in responding to the needs of students with disabilities. Similarly, according to the FOTIM study, some small Disability Units at historically black universities showed innovation and emerging best practice features with regards to service provision for students with disabilities.

Financial constraints also affect the operation of Disability Units, especially for historically black higher education institutions (FOTIM 2011; Howell 2005; Matshedisho 2007a). Lack of resources leads to other Disability Units being understaffed (Naidoo 2010; Sukhraj-Ely 2008; Tugli et al. 2013), resulting in delays in students receiving study material (Naidoo 2010). It is important to note that it is not always the case that students with disabilities do not receive good services at historically black higher education institutions. Despite financial challenges, some 
Disability Units at historically black universities make positive contributions to the lives of their students (Howell 2005). In a study on information-seeking behaviour in blind and visually impaired students at the University of KwaZulu-Natal, Pietermaritzburg campus, Seyama, Morris and Stilwell (2014) revealed that the students included the Disability Unit staff as an indispensable part of information access.

Despite the positive role of Disability Units towards full inclusion of students with disabilities, they have limitations and challenges. They are not autonomous as they fall under different departments (e.g. student counselling or student affairs) and this restricts them in the services they can provide (FOTIM 2011; Naidoo 2010). The approach of some departments oppose the direction some Disability Units want to take e.g. those Disability Units managed within Counselling Services viewed disability through a pathological lens and reinforced the perspective that disability is a medical condition (Lyner-Cleophas, Swart, Chataika and Bell 2014). In other institutions, there are no disability policies (Maotoana 2014; Mutanga 2015). Others have pointed that the establishment of Disability Units has also kept people with disabilities out of mainstream higher education activities as they are separated from the rest of the student population (DHET 2013; FOTIM 2011).

The importance of Disability Units in the lives of students with disabilities cannot be denied. However, caution is needed to avoid stereotyping students with disabilities and alienating them from the rest of the student population, while maintaining the same dominant culture that views people with disabilities as second-class citizens, who must be helped by a Disability Unit to fit into an 'unchanging' higher education system. Disability Units should not be seen as the only way of responding to the needs of students with disabilities. Given the position of Disability Units in relation to the needs of students as shown by the literature, it is important to critically interrogate their role against principles of social justice i.e. their ability to create opportunities for all students to fully participate and succeed in higher education in order for them to reach their goals and fulfil their aspirations.

\section{The role of lecturers}

South African literature also reports on students with disabilities perceptions of the conduct of lecturers. Some students perceive that lecturers' lack of disability awareness results in failing to make necessary provisions (Matshedisho 2010; Haywood 2014). Swart and Greyling (2011) found that students in the Humanities and Social Sciences were more positive about the support they receive from lecturers than students in the Natural, Economic and Business Sciences. Focusing on one HEI, Ohajunwa et al. (2014) investigated whether and how disability issues 
are included in the teaching and research of three faculties: Health Sciences, Humanities, and Engineering and the Built Environment at the University of Cape Town. Similar to Swart and Greyling (2011) and Greyling (2008), their studies reveal low levels of disability inclusion and disability not being viewed as an issue of social justice. However, there were pockets of inclusion, the nature of which differed from faculty to faculty. In the Faculty of Engineering and the Built Environment, disability was included as an issue of legislation, space and environment. At the Faculty of Humanities the focus is on the sociocultural and economic impact of disability. The Faculty of Health Sciences introduces disability with an emphasis on individual impairment, environmental effects, community-based rehabilitation and inclusive development, as well as the prevention and management of disability. The authors propose the creation of an institutional system that will build the capacity of lecturers to include disability in teaching and research across all faculties, in line with the university's transformation agenda. This recommendation is supported by Crous (2004), who found that 67 per cent of students with disabilities in his study believed that their lecturers had limited knowledge of disability issues.

Lack of awareness on the part of lecturers was also highlighted by Mayat and Amosun (2011) in their study, which explored the perceptions of academic staff regarding admission of students with disabilities, and their accommodation once accepted into a Civil Engineering program at a South African university. They noted that students with disabilities in South Africa are still excluded from certain academic fields, such as engineering and natural sciences. Even though the five participating staff expressed willingness to teach students with disabilities, they showed some reservations. The authors state that participants were concerned about the perceived limitations of students with disabilities, and worried that they would not be able to meet all the course requirements. One lecturer even wondered whether students with disabilities would be an 'embarrassment' to their non-disabled peers. These perceptions exclude students with disabilities from participating in academic programmes they might want to pursue. Considering two Technical and Vocational Education and Training (TVET) colleges, NgubaneMokiwa and Khoza (2016) note that students with disabilities are not supported technologically in terms of their learning as result of lecturers’ lack of knowledge, teaching approaches and resources.

Another study on the role of lecturers is Van Jaarsveldt and Ndeya-Ndereya's (2015) study on the e-learning needs of students with disabilities at a South African university. Some lecturers distanced themselves from the responsibility of providing support to students with disabilities. These lecturers displayed a lack of involvement with the students and tended to 
refer them to the Disability Unit. An inclusive learning environment at this university remains elusive. The authors argue that although higher education institutions' disability policies are necessary, personal responsibility from lecturers is also essential in bringing about inclusive campuses.

While these studies clearly show a need for understanding how lecturers from different departments understand and experience disability, differences across faculties and among lecturers point to an absence of embedding of institutional disability policy and practices within higher education institutions. It is clear that support for students with disabilities is dependent on the Disability Units and individual lecturers. It is therefore important to understand the attitude and views of lecturers with regards to students with disabilities. A vital area which requires further exploration is the reasons behind the lack of involvement from some lecturers.

\section{The role of assistive technology}

While assistive technology enhances access to learning for students with disabilities, at times it excludes other students. To ensure that they do not perpetuate injustices, the role of assistive technologies is key in the creation of inclusive environments. For example, in their study on the learning experiences of visually-impaired students, Mokiwa and Phasha (2012) report that Job Access With Speech (JAWS) software for visually-impaired students could not read mathematical and scientific signs or graphic material. Furthermore, multi-digital technology in the form of PowerPoint presentations or other visual technology was unhelpful to visuallyimpaired students (Sukhraj-Ely 2008). Similarly, Kajee’s (2010) study (of a technology-based English course that incorporates face-to-face and online modes of delivery at a South African university) reported how the only visually-impaired student in the class often felt powerless and isolated, as a result of pedagogical challenges presented by these technologies. These studies highlight a need to be cautious and to continuously interrogate the systems designed to help students with disabilities, as they have the potential to create disadvantages for the very people they are supposed to help. In the midst of these challenges, there were enabling factors that assisted students with disabilities.

\section{Enabling factors}

The positive contributions of family, friends, non-academic staff, and some academic staff are highlighted in three studies. In one of the few studies that engaged students with disabilities, Matshedisho (2010) interviewed thirty students with disabilities from different higher education institutions, who answered a self-administered questionnaire via their respective Disability 
Units. Most students attributed their success to the supportive friends they made during induction. With regards to the attitudes of academic staff, students had mixed reactions: some reported positive attitudes, while others had bad experiences. The importance of social networks and social relations is highlighted by Roux and Burnett (2010) in their exploratory study involving four students with disabilities, who were elite sport participants from the University of Johannesburg. Some challenges were identified within the university (e.g. visibility of stairs, inaccessible infrastructure and some exclusionary practices in sports). However, these students were managing through a network of support from family, friends and coaches. Roux and Burnett concluded that students with disabilities in higher education should be encouraged to participate in decision-making to meet their special needs. Lastly, in his study on deaf teachers' experiences as students at the University of Witwatersrand, Magogwa (2008) found high levels of academic success among the deaf students owing to the institutional commitment to deaf education, through (for example) the availability of interpreting services.

These three studies highlight the importance of support from family, friends, academic and non-academic staff in the creation of inclusive higher education. Differences in the attitudes of academic staff in Matshedisho’s (2010) study suggests that not all academic staff are negative towards students with disabilities: it is important to recognise that others have a positive attitude. Knowing how and why staff behave the way they do is an important area of inquiry that needs further exploration (Mutanga and Walker 2017). The experiences of students with disabilities reflect a product of iterative interactions with the environment (physical, social, political and economic) and individual agency. Thus, considerations of a just-disability policy cannot be secondary to the study of one's environment, but must be integrated with it.

In a quantitative study at three South African universities (the largest distance learning university and two large residential universities), Crous (2004) found that 63 per cent of participating students did not disclose their disability to lecturers. Students were sometimes under the impression that Disability Units or university administration would do this for them, but in many instances, this did not happen. It is evident that not all students exercise their agency, and although some students cope effectively in the midst of challenges, government and higher education institutions should not neglect their duty to create inclusive environments for all students. Below I discuss the implications of these studies.

\section{DISCUSSION}

Although South Africa has a persuasive policy framework aimed at improving equity and inclusion of students with disabilities in higher education, these empirical studies highlight that 
there is still a long way to go in realising equal access and participation. Literature points to complexities around disability issues in higher education. Of particular interest are the findings of Ohajunwa et al. (2014), who state that disability is not viewed as an issue of social justice in SAHE and propose that most challenges faced by students with disabilities can be solved through curricula. Given the myriad of challenges highlighted in the reviewed literature, disability issues benefit from being viewed as a matter of social justice, and this is where the capabilities approach fits in. This is closely related to the fact that most of the studies reported here are small, because they are student projects (at Master and doctoral levels) and thus likely to be conducted quickly and cheaply. There is an assumption that if a programme targets 'students with disabilities', all students with disabilities will benefit equally. The reality is that without clear data and specific policy decisions, students with disabilities do not benefit equally from programmes that treat students with disabilities as a homogenous group. In order to develop beneficial policies, disability data disaggregated from larger studies is essential.

Students with disabilities in higher education are faced with complex challenges. Although some studies state that they are influenced by the social model, as has been shown in this article, on its own, the model cannot give us the whole picture of the experiences of students with disabilities in SAHE. A holistic explanation is possible through a framework that allows multiple perspectives to understand disability issues. The capabilities approach does so by offering higher education and disability policy-makers tools to question the extent to which students' opportunities are being promoted or inhibited within and across different higher education institutions. Focusing on students' opportunities and well-being makes it possible to move beyond evaluating educational success based only on students' performance in exams and graduation rates. We can measure the gap between the lived experiences of students with disabilities and what they value in higher education (Mutanga 2015). This is one of the methods that shows the significance of the capabilities approach compared to other disability models. Inclusive education from a capabilities-based social justice framework demands expanding opportunities for students by attending to their needs, so that they can access knowledge and acquire skills, just like other students.

As has been acknowledged, 'an expanded higher education sector that offers opportunities to develop the skills and knowledge required for society's flourishing even at the basic education level (through the production of teachers, administrators and policy-makers) must be developed' (Mutanga 2014, 449). As can be seen from the reviewed literature, much is known about students with disabilities in SAHE. It is not that we know nothing about students with disabilities; rather, there is a lack of political will on part of the government and higher 
education institutions. As such, students with disabilities need to contribute to the development of inclusive campuses. This is not to suggest that they are at fault, but when no-one is reacting, the victims need to take action.

Furthermore, when one looks at the findings from the studies presented here, the importance of seeing a student with disability as a dependent part of a group (or groups) as well as an individual operating within a specific personal, social, economic and familial context that may be quite different from the context of other students with disabilities, is clear. Hart (2011, 2) argues that 'whilst significant group differences can be helpful in indicating patterns of inequality this is not adequate to comprehensively identify disadvantage for specific individuals'. Although common challenges for students with disabilities cannot be denied, it would be wrong to assume that all students with disabilities, for example, all face physical access challenges. Students who use wheelchairs and those with visual challenges are those most affected by physical environment arrangements.

This literature review has shown that students with disabilities continue to face different challenges in higher education owing to a lack of policy. However, this might suggest that there are no successful experiences among students with disabilities. Little attention has been given to positive experiences of students with disabilities in higher education because most studies have not approached disability issues through a lens that takes into account students' agency.

These studies have looked at the experience of students with disabilities from two angles. On the one hand, some scholars have focused on a single impairment, while other scholars explore the experiences of students with varied impairments. In all cases, the experiences of students with disabilities are highlighted, but it is those studies that focus on different types of impairments that allow the complexities in the academic lives of students with disabilities to emerge most clearly. It is evident that different individuals with different impairments face unique challenges and experiences. Evidence also highlights both the variability of students with disabilities' experience as well as some connections with other non-disabled students. This challenges the obscuring areas of commonality that exist between the experiences of students with disabilities and non-disabled students in higher education. In order to obtain a richer picture, large-scale studies focusing on both students with varied impairments and non-disabled students are necessary.

Although some of these studies highlight issues of inclusion and participation of students with disabilities linked to their success or failure in higher education, the views of non-academic staff and higher education administrators are missing in most of the South African literature. It is important to know what does and does not work for the non-academic staff in their quest to 
create inclusive environments for students with disabilities. This is also true for higher education managers and administrators, whose voices are absent from most of the reviewed studies. Their views will help dialogue and debate with and among institutions about the best inclusive practices.

\section{CONCLUSION}

In this article, I have generated a narrative review of the South African literature focused on students with disabilities in SAHE. I have highlighted the main findings from these studies as well as their deficiencies, and suggested a new approach to framing and looking at disability issues. It is evident that the difficulties in providing adequate support services for students with disabilities reflect some significant gaps between policy and practice. From the reviewed literature, it is apparent that accessing higher education does not ultimately result in inclusion and full participation for students with disabilities. Complex challenges still exist and have been highlighted since 2003. Improving the experiences of students with disabilities requires institutional effort, both wide in scope and systemic in nature. Without blaming them, students with disabilities need to be equipped to politically confront the political players. Lastly, I suggested that the capabilities approach helps us understand disability issues as well as giving a framework that can help in designing disability-inclusive policies.

\section{Funding details}

The research reported on here was supported by the South African Research Chairs Initiative of the Department of Science and Technology and National Research Foundation of South Africa, grant number 86540.

\section{Disclosure details}

I declare that we have no financial or personal relationships which may have inappropriately influenced our writing this article.

\section{REFERENCES}

Bell, D. 2013. Investigating teaching and learning support for students with hearing impairment at a university in the Western Cape. Doctoral thesis. University of Stellenbosch: South Africa.

Bell, D., A. Carl and E. Swart. 2016. Students with hearing impairment at a South African university: Self-identity and disclosure. African Journal of Disability 5(1): a229. http://dx.doi.org/ 10.4102/ajod.v5i1.229

Buthelezi, M. M. 2014. Exploring challenges experienced by physically challenged students at a Further Education and Training College in KwaZulu-Natal Province. Master's thesis. University of South Africa. 
Crous, S. F. M. 2004. The academic support needs of students with impairments at three higher education institutions. South African Journal of Higher Education 18(1): 228-251.

Department of Education. 2001. National Plan for Higher Education. Pretoria: Department of Education.

Department of Higher Education and Training. 2013. White paper on post-school education and training. http://www.dhet.gov.za/SiteAssets/Latest\%20News/White\%20paper\%20for\%20postschool\%20education\%20and\%20training.pdf (accessed 8 January 2013).

DHET see Department of Higher Education and Training.

DOE see Department of Education.

Engelbrecht, L. and J. J. de Beer. 2014. Access constraints experienced by physically disabled students at a South African higher education institution. Africa Education Review 11(4): 544-562.

Fitchett, A. 2015. Exploring adaptive co-management as a means to improving accessibility for people with reduced mobility at the University of Witwatersrand. In Making education inclusive, ed. E. Walton and S. Moonsamy. Cambridge Scholars Publishing: Newcastle upon Tyne.

FOTIM see Foundation of Tertiary Institutions of the Northern MetroPolis.

Foundation of Tertiary Institutions of the Northern MetroPolis. 2011. Disability in higher education project report. Retrieved from http://www.uct.ac.za/usr/disability/reports/progress_report10 _11.pdf (accessed 10 February 2013).

Greyling, E. 2008. Students with disabilities' experiences of support and barriers to their development at Stellenbosch University. Master's thesis. Stellenbosch University, South Africa.

Hart, C. S. 2011. Thinking, being, doing: Capabilities in relation to decision-making and transitions beyond school in the UK. Paper presented at the 2011 Conference on Children's Capabilities and Human Development, University of Cambridge, April 11-12.

Haywood, C. 2014. The opinions of lecturers at a university of technology regarding their role in supporting students experiencing barriers to learning. Master's thesis. North West University, South Africa.

Howell, C. 2005. South Africa higher education responses to students with disabilities. Equity of access and opportunity? Higher Education Monitor no. 23. Pretoria: The Council on Higher Education.

Howell, C. 2006. Disabled students and higher education in South Africa. In Disability and social change, ed. B. Watermayer, L. Swartz, T. Lorenzo, M. Schneider and M. Priestley, 164-178. Human Sciences Research Council Press: Cape Town.

Howell, C. and S. Lazarus. 2003. Access and participation for students with disabilities in South African higher education: Challenging accepted truths and recognising new possibilities. Perspectives in Education 21(3): 59-74.

Kajee, L. 2010. Disability, social inclusion and technological positioning in a South African higher education institution: Carmen's story. The Language Learning Journal 38(3): 379-392.

Ladau, E. 2015. Why person-first language doesn't always put the person first. Think inclusive. http://www.thinkinclusive.us/why-person-first-language-doesnt-always-put-the-person-first/ (accessed 6 March 2016).

Losinsky, L. O., T. Levi, K. Saffey and J. Jelsma. 2003. An investigation into the physical accessibility to wheelchair bound students in an institution of higher learning in South Africa. Disability and Rehabilitation 25: 305-308.

Lourens, H. 2015. The lived experiences of higher education for students with a visual impairment: A phenomenological study at two universities in the Western Cape. Doctoral thesis. Stellenbosch University. South Africa.

Lourens, H. and L. Swartz. 2016. Experiences of visually impaired students in higher education: Bodily perspectives on inclusive education. Disability and Society 31(2): 240-251.

Lourens, H., E. L. McKinney and L. Swartz. 2016. Disability and education: More than just access. In 
The Palgrave international handbook of education for citizenship and social justice, ed. A. Peterson, R. Hattam, M. Zembylas and J. Arthur. Palgrave Macmillan: UK.

Lyner-Cleophas, M., E. Swart, T. Chataika and D. Bell. 2014. Increasing access into higher education: Insights from the 2011 African network on evidence-to-action on disability symposium. African Journal of Disability 3(2): 78-80.

Magogwa, L. 2008. Deaf teachers' experience of being students at the University of the Witwatersrand. Master's thesis. University of the Witwatersrand, South Africa.

Maotoana, M. R. 2014. The challenges experienced by Students with Physical Disability (SWPD's) at the University of Limpopo (Turfloop Campus). Master's thesis. University of Limpopo, South Africa.

Matshedisho, K. R. 2007a. The challenge of real rights for disabled students in South Africa. South African Journal of Higher Education 21(4): 706-716.

Matshedisho K. R. 2007b. Access to higher education for disabled students in South Africa: A contradictory conjuncture of benevolence, rights and the social model of disability. Disability and Society 22(7): 685-699.

Matshedisho, K. R. 2010. Experiences of disabled students in South Africa: Extending the thinking behind disability support. South African Journal of Higher Education 24(5): 730-744.

Mayat, N. and S. L. Amosun. 2011. Perceptions of academic staff towards accommodating students with disabilities in a Civil Engineering Undergraduate Program in a university in South Africa. Journal of Postsecondary Education and Disability 24(1): 53-59.

Mitra, S. 2006. The capability approach and disability. Journal of Disability Policy Studies 16: 236247.

Mokiwa, S. A. and T. N. Phasha. 2012. Using ICT at an open distance learning (ODL) institution in South Africa: The learning experiences of students with visual impairments. Africa Education Review 9(1): 136-151.

Morrison, J., H. Brand and C. Cilliers. 2009. Students with disabilities in higher education. Acta Academica 41(3): 201-223.

Mutanga, O. 2013. 'I am a university student, not a disabled student': Conceptualising identity and social justice in South African higher education through the capabilities approach lens. Journal of Educational Studies 12(1): 76-88.

Mutanga, O. 2014. The role of basic education, higher education and capability lists. Journal of Human Development and Capabilities 15(4): 448-451.

Mutanga, O. 2015. Experiences of disabled students at two South African universities: A capabilities approach. Doctoral thesis. University of the Free State, South Africa.

Mutanga, O. and M. Walker. 2015. Towards a disability-inclusive higher education policy through the capabilities approach. Journal of Human Development and Capabilities 16(4): 501-517.

Mutanga, O. and M. Walker. 2017. Exploration of the academic lives of students with disabilities at South African universities: Lecturers’ perspectives. African Journal of Disabilities 6: 1-11.

Naidoo, A. 2010. Students with disabilities' perceptions and experiences of the disability unit at the University of Kwazulu-Natal: Howard college campus. Master's dissertation. University of KwaZulu Natal, South Africa.

Naicker, S. M. 2005. Inclusive education in South Africa: An emerging pedagogy of possibility. In Contextualizing inclusive education, ed. D. Mitchell, 230-252. Abingdon, UK: Routledge.

Ndlovu, S. and E. Walton. 2016. Preparation of students with disabilities to graduate into professions in the South African context of higher learning: Obstacles and opportunities. African Journal of Disability 5(1), Art. \#150. http://dx.doi.org/10.4102/ajod.v5i1.150

Ngubane-Mokiwa, S. and S. B. Khoza. 2016. Lecturers' experiences of teaching STEM to students with disabilities. Journal of Learning for Development - JL4D, [S.1.], 3(1): 2311-1550. http://j14d.org/ index.php/ejl4d/article/view/125/121 (accessed 22 February 2017). 
Nel, M., P. Engelbrecht, N. Nel and D. Tlale. 2013. South African teachers' views of collaboration within an inclusive education system. International Journal of Inclusive Education 18: 903-917.

Ntombela, S. and R. Soobrayen. 2013. Access challenges for students with disabilities at the University of KwaZulu-Natal: A situational analysis of the Edgewood Campus. Journal of Social Sciences 37(2): 149-155.

Nussbaum, M. 2006. Frontiers of justice: Disability, nationality, species membership. Cambridge, Mass: Belknap Press.

Nussbaum, M. 2011. Creating capabilities. Cambridge, MA, The Belknap Press.

Ohajunwa, C., J. Mckenzie, A. Hardy and T. Lorenzo. 2014. Inclusion of disability issues in teaching and research in higher education. Perspectives in Education 32(3): 104-117.

Phukubje, J. and M. Ngoepe. 2016. Convenience and accessibility of library services to students with disabilities at the University of Limpopo in South Africa. Journal of Librarianship and Information Science: 1-11.

Roux, C. J. and C. Burnett. 2010. The extent to which students with disabilities are included in elite sports at Higher Education Institutions. African Journal for Physical, Health Education, Recreation and Dance December (supplement): 120-131.

Sen, A. K. 1999. Development as freedom. New York: Knopf.

Seyama, L., C. D. Morris and C. Stilwell. 2014. Information seeking behaviour of blind and visually impaired students: A case study of the University of KwaZulu-Natal, Pietermaritzburg Campus. Mousaion: SA Journal of Information Studies 32(1): 1-22.

Strnadova, I., V. Hájková and L. Květoňová. 2015. Voices of university students with disabilities: Inclusive education on the tertiary level - a reality or a distant dream? International Journal of Inclusive Education 19(10): 1080-1095.

Sukhraj-Ely, P. 2008. Inclusive education policy and practice: Investigating the educational rights and needs of learners and students with visual impairments in South Africa. Doctoral thesis, University of Kwazulu-Natal, South Africa.

Swart, E. and E. Greyling. 2011. Participation in higher education: Experiences of students with disabilities. Acta Academica 43(4): 80-110.

Swart, E. and R. Pettipher. 2011. Perspectives on inclusive education. In Addressing barriers to learning in South Africa, ed. E. Landsberg, D. Kruger and E. Swart, 1-27. Pretoria, South Africa: Van Schaik.

Tugli, A. K., L. I. Zungu, D. T. Goon and F. C. Anyanwu. 2013. Perceptions of students with disabilities concerning access and support in the learning environment of a rural-based university. African Journal for Physical, Health Education, Recreation and Dance: 356-364.

Van Jaarsveldt, D. E. and C. N. Ndeya-Ndereya. 2015. 'It's not my problem': Exploring lecturers' distancing behaviour towards students with disabilities. Disability and Society 30(2): 199-212.

Watermeyer, B., L. Swartz, T. Lorenzo, H. Schneider, M. Priestley and M. Schneider. 2006. Disability and social change: A South African agenda. Cape Town: HSRC Press. 